\title{
The effects of water on the morphology and the swelling behavior of sulfonated poly(ether ether ketone) films
}

\author{
B. T. Koziara ${ }^{1} \cdot$ N. Akkilic ${ }^{1}$ K. Nijmeijer ${ }^{1}$ - N. E. Benes ${ }^{2}$ (I)
}

Received: 22 June 2015/ Accepted: 12 September 2015/Published online: 29 September 2015

(c) The Author(s) 2015. This article is published with open access at Springerlink.com

\begin{abstract}
Thin sulfonated poly(ether ether ketone) films swell excessively in water. The extent of water-induced swelling is shown to be correlated with the optical anisotropy of the films, due to two distinct phenomena. Firstly, the optical anisotropy is directly related to the amount of water taken up from the surrounding ambient atmosphere, and thus to amount of water present in the material just prior to swelling. Secondly, the optical anisotropy corresponds to internal stresses in the film that affect the free energy of the film, and thus the potential of the film to swell. The anisotropy vanishes upon sorption of liquid water and returns when the water is desorbed. When the water is completely removed, the film changes from more or less colorless to an intense yellow color that can be attributed to molecular assembly of the aromatic rings in the polymer backbone. The color change is reversible and occurs immediately upon exposure to low humidity. For films prepared in the absence of water, the lack of
\end{abstract}

\section{N. E. Benes \\ n.e.benes@utwente.nl \\ B. T. Koziara \\ b.t.koziara@utwente.nl \\ N. Akkilic \\ n.akkilic@utwente.nl \\ K. Nijmeijer \\ d.c.nijmeijer@utwente.nl}

1 Department of Science and Technology, Membrane Science \& Technology, The Mesa+ Institute for Nanotechnology, University of Twente, P.O. Box 217, 7500 AE Enschede, The Netherlands

2 Department of Science and Technology, Films in Fluids/ Inorganic Membranes, The Mesa+ Institute for Nanotechnology, University of Twente, P.O. Box 217, 7500 AE Enschede, The Netherlands hydration of the sulfonic acid groups affects the microphase separation behavior of the polymer. This is manifested by an apparent lower propensity to water-induced swelling. The possibility to affect the properties of sulfonated polymer films by varying the hydration state of the polymer during preparation can have important implications for applications of such films.

\section{Introduction}

Membranes from highly sulfonated poly(ether ether ketone) (SPEEK) strongly swell upon contact with water. This is due to the high affinity that water has for the sulfonic acid groups in SPEEK. For some applications, a high concentration of water in the polymer can be beneficial, for instance, to facilitate proton transport in fuel cells [1] or for the dehydration performance [2-4]. A drawback of too excessive swelling is the reduced mechanical strength that may lead to ruptures, in particular in the case of thin films that are constrained on a substrate. Constrained films can only swell in a single direction, and at a similar degree of swelling, the elastic deformation of their network is thus more pronounced as compared to free-standing films [5]. Excessive swelling is also known to have an impact on the performance of membranes in molecular separation. In general, swelling leads to larger fluxes of all species present, and causes drastic reductions in selectivity. Much effort has been devoted to the reinforcement of SPEEK films. Approaches include chemical modifications, such as covalent and ionic cross-linking [6], doping with inorganic particles $[7,8]$ and creating structures with integrated skin layers [9].

The relations between swelling, proton transport, and the chemical and intermolecular structure of SPEEK and 
other sulfonated polyelectrolyte films have been studied extensively [10-12]. The performance of membranes made from these polymers is reported to be affected by molecular orientations and chain assembly. Zhang et al. reported that SPEEK films with the same chemical structure (i.e., with a degree of sulfonation of $40 \%$ ) but formed at various relative humidity degrees, exhibit distinct molecular arrangement, and orientation of the sulfonic acid groups [13]. The proton conductivity performance of those membranes is dissimilar. This implies that the proton transport characteristics of SPEEK are not only dictated by the amount of sulfonic acid groups, but also by their molecular arrangement. It can be anticipated that the molecular structural arrangements of SPEEK will also affect the swelling behavior upon contact with water.

In a previous study, we reported that thin SPEEK films exhibit certain structural arrangements, in particular, inherent orientations in the in-plane direction [14]. In short, SPEEK films, independently on the preparation route and formation procedure, are preferentially oriented in the $x y$ direction as compared to the $z$ direction [14]. This is manifested by optical anisotropy $\Delta n$, i.e., $\Delta n=n_{x y}-$ $n_{z}>0$. In this expression, $n_{x y}$ is the in-plane refractive index and $n_{z}$ is the out-of plane refractive index. In the present paper, we study the relations between those structural arrangements of supported thin SPEEK films and (the dynamics of) their water-induced swelling, to assess if swelling can be significantly affected without chemical modification of the polymer.

The paper comprises two parts. In the first part, the focus is on the correlation between optical anisotropy and swelling. In the second part, the focus is on presence of water on the molecular assembly of the aromatic rings in the polymer backbone, and on the microphase behavior during film formation in the absence of water.

\section{Materials and methods}

\section{Materials}

Two batches of SPEEK polymer were used: SPEEK with a degree of sulfonation (DS) $84 \%$-homemade, obtained by sulfonation of PEEK (Victrex) using sulfuric acid according to the procedure described elsewhere [15], and SPEEK DS $68 \%$-fumion ${ }^{\circledR}$ ELM-505 obtained from Fumatech (Germany) as $5 \mathrm{wt} \%$ solution of methanol. Methanol (Emsure $^{\circledR}$ grade of purity) was obtained from Merck (The Netherlands). Rhodamine $6 \mathrm{G}$ was obtained from SigmaAldrich (The Netherlands). $\langle 100\rangle$-oriented silicon wafers P/Boron were obtained from Okmetic (Finland). Quartz glass slides Nr. 1.5 were obtained from Menzel Gläser (Germany). Nylon Membrane $25 \mathrm{~mm}$ syringe filters
$0.45 \mu \mathrm{m}$ were obtained from VWR International. Porous $\alpha$ alumina disks were purchased from Pervatech (The Netherlands). Nitrogen gas (4.5) was supplied by Linde (Germany). Deionized water $(18.2 \mathrm{M} \Omega \cdot \mathrm{cm})$ was obtained using a Milli-Q Advantage A10 system (Millipore).

\section{Film preparation}

\section{For spectroscopic ellipsometry}

Films were spin-coated from SPEEK $5 \mathrm{wt} \%$ dissolved in methanol on pre-cut pieces of silicon wafers. Prior to spincoating, the solutions were filtered using a syringe filter in order to remove residual contaminations. SPEEK in the $5 \mathrm{wt} \%$ methanol solution from Fumatech has a relatively high molecular weight and correspondingly high viscosity. The solution was diluted with methanol (SPEEK solution to fresh methanol volume ratio was $3.5: 1$ ) prior to spincoating to decrease the viscosity, such that all films for swelling experiments are $\sim 300 \mathrm{~nm}$ thick. Spin-coating was conducted under two distinct humidity conditions:

Humid atmosphere Spin-coating was conducted in air, at ambient relative humidity. The spin speed was set at 2000 or $3000 \mathrm{rpm}$.

Dry atmosphere Spin-coating was conducted under a large stream of dry nitrogen $(R H=0 \%)$. The spin speed was always set at $2000 \mathrm{rpm}$.

The spinning time was set to $50 \mathrm{~s}$. Directly after spincoating, the films were conditioned under vacuum at $140{ }^{\circ} \mathrm{C}$ for $48 \mathrm{~h}$. This procedure is implemented to induce non-covalent attachment of the film to the substrate and to prevent detachment of the film upon swelling.

Before water swelling experiments, all films were equilibrated directly after removal from a vacuum oven, at the ambient relative humidity degree, and characterized subsequently ex situ using spectroscopic ellipsometry (SE). The equilibration time was about $30 \mathrm{~min}$ for single experiments, in case of multiple experiments (several samples measured in a row) this time had to extend. The following nomenclature is used to describe the samples: degree of sulfonation-spin speed_formation atmosphere$R H$ of equilibration atmosphere; example: 84-2000_humid40 denotes a SPEEK film with a $D S$ of $84 \%$, formed at $2000 \mathrm{rpm}$ in a humid atmosphere and equilibrated before swelling experiment in surrounding ambient atmosphere of $R H=40 \%$.

The details of ex situ characterization of thin SPEEK films using SE have been described in our previous paper [14]. That paper shows that SPEEK films always exhibit optical anisotropy which is a result of the internal stresses present in the films, due to preferential orientations of the 
polymer chains [14]. The internal stresses and consequently, optical anisotropy in SPEEK films, decrease upon sorption of plasticizers, such as water or organic solvents $[14,16]$. Consequently, the increase of the relative humidity degree $(\mathrm{RH} \%)$ of the surrounding ambient atmosphere, to which films are exposed after the formation procedure, results in an increased water vapor sorption and therefore, in depression of optical anisotropy. On the contrary, sample drying/water desorption causes increase of optical anisotropy. Table 1 shows the approximate values of optical anisotropy of the SPEEK films investigated in this paper for swelling experiments that are affected by, as mentioned, $R H$ of the surrounding ambient atmosphere during sample equilibration, and additionally, by the spin speed used in spin-coating [14]. Moreover, no variations of optical anisotropy and refractive indices as a function of the substrate radius/position were found for thin SPEEK films, only the shear thinning behavior was observed [14]. Therefore, it is not of importance which sample spot is measured for swelling experiments, as long as the thickness of this spot is recorded.

The initial thickness of the films used for swelling experiments was in the range $280-350 \mathrm{~nm}$. We assumed no impact of the film thickness in this range on swelling behavior.

\section{For fluorescence microscopy}

Two methods were applied to prepare SPEEK films with the protons of the negatively charged sulfonic acid groups being exchanged with the cationic fluorescent dye. (1) Films were spin-coated from a mixture of $3 \mathrm{wt} \%$ SPEEK in methanol and Rhodamine $6 \mathrm{G}$ on quartz glass slides at $2000 \mathrm{rpm}$. The molar ratio of Rhodamine $6 \mathrm{G} /$ sulfonic acid groups was $6 \times 10^{-9}$. Alternatively, (2) films were spincoated from $3 \mathrm{wt} \%$ SPEEK in methanol at $2000 \mathrm{rpm}$, without Rhodamine $6 \mathrm{G}$ in the solution. Subsequently, $0.1 \mathrm{ml}$ of the Rhodamine $6 \mathrm{G}$ water solution was deposited, with the similar molar ratio as in the first method, on the film surface and left for $2 \mathrm{~h}$.

Table 1 The approximate dependency of optical anisotropy in thin SPEEK films on the $R H$ of the ambient atmosphere during sample equilibration at room temperature and on the spin speed during spincoating

\begin{tabular}{lll}
\hline $\begin{array}{l}\text { Optical } \\
\text { anisotropy } \\
\Delta n(-)\end{array}$ & $\begin{array}{l}R H \text { of the ambient atmosphere } \\
\text { during sample equilibration }(\%)\end{array}$ & $\begin{array}{l}\text { Spin speed } \\
\text { during spin- } \\
\text { coating (rpm) }\end{array}$ \\
\hline $0.043-0.041$ & $20-40$ & 3000 \\
$0.028-0.025$ & $20-40$ & 2000 \\
$0.023-0.014$ & $50-90$ & 2000 \\
\hline
\end{tabular}

Spin-coating was done in humid and dry atmosphere, as described above for the film formation for spectroscopic ellipsometry. The thicknesses of the films for fluorescence microscopy were $\sim 150 \mathrm{~nm}$.

\section{Films on porous alumina supports}

Films were spin-coated on porous $\alpha$-alumina supports, which were coated with a single layer of $\gamma$-alumina (according to the procedure described by Luiten et al. [17]), from $10 \mathrm{wt} \%$ SPEEK dissolved in methanol, under humid ambient $(R H=60 \%)$ and dry atmosphere $(R H=0 \%)$ at $2000 \mathrm{rpm}$. The thicknesses of the films were $\sim 800 \mathrm{~nm}$.

\section{Measurements}

\section{Spectroscopic ellipsometry (SE)}

SE experiments were performed on two devices: alfa-SE and M-2000 (J.A. Woollam Co., Inc.). The size spot of the light beam was $2 \mathrm{~mm}$ and a $70^{\circ}$ angle of incidence was applied for ex situ and in situ measurements. In situ measurements were conducted in demineralized liquid water at a temperature of either 20 or $40{ }^{\circ} \mathrm{C}$ using a custom-made temperature-controlled $70 \mathrm{~mL}$-volume glass cell [18]. A photo of the experimental set-up is shown in Fig. 1. The temperature-controlled glass cell (here filled with water) is located between the light source (left arm) and the detector (right arm) of the ellipsometer. A SPEEK film is placed in the glass cell and the set-up is aligned in such a way that the incident polarized light hits, and is reflected from the sample at $70^{\circ}$, and hits the detector. For more details about SE technique, the interested reader is referred to Tompkins et al. [19] or Fujiwara [20].

For water experiments in the glass cell, the delta offset was determined prior to measurements using a calibration wafer. The recording of the swelling data started in the first half minute after immersion in water. Modeling of the data obtained from SPEEK film measurements using CompleteEase 4.64 software (J.A. Woollam Co., Inc.) is described in detail in our previous paper [14]. The ambient refractive index of water at 20 and $40{ }^{\circ} \mathrm{C}$ was taken from the $\mathrm{H}_{2} \mathrm{O}$ Pribil Temperature Library from the CompleteEase software.

The time-dependent swelling factor $S_{F(t)}=d(t) / d_{\text {initial }}$ is defined as the thickness $d$ at time $t$ normalized with respect to the initial thickness. The initial film thickness is measured by ex situ ellipsometry prior to the swelling experiment. After immersion of the sample in liquid water, the ellipsometer has to be aligned prior to recording of the data. Therefore, the data at the time $t=0-0.5 \mathrm{~min}$ are lost. Consequently, the initial values of swelling factors shown in the graphs are always $>1$ because these correspond to $t>0.5 \mathrm{~min}$. 


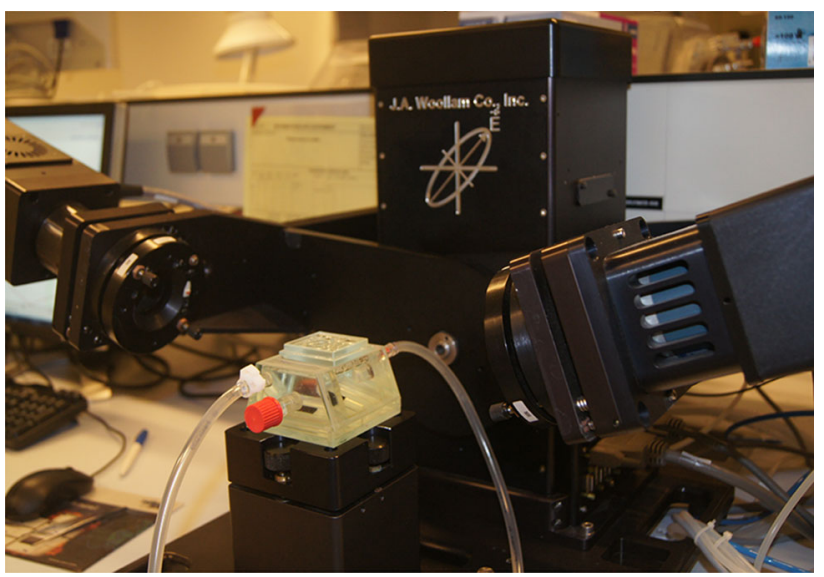

Fig. 1 Photo of the experimental set-up: J. A. Woollam Co., Inc. M-2000 ellipsometer with the custom-made temperature-controlled glass cell [18]

\section{Total internal reflection fluorescence microscopy (TIRF)}

TIRF microscopy was performed using a Nikon Eclipse Ti microscope equipped with a $100 \times$ Oil, Plan Apo objective (numerical aperture 1.45, Olympus) and an Andor DU-885 camera in TIRF mode. The Rhodamine $6 \mathrm{G}$ was excited using a $488 \mathrm{~nm}$ laser with a readout speed of $35 \mathrm{MHz}$. The emission signal from the green dye was collected at $520 \mathrm{~nm}$.

\section{Results and discussion}

\section{The effect of anisotropy on swelling of thin films formed at $R H \geq 20 \%$}

Figure 2 shows the swelling dynamics for two distinct SPEEK films, prepared from the same polymer batch, $D S$ $84 \%$ and formed under humid conditions at $2000 \mathrm{rpm}$, upon exposure to liquid water at $40{ }^{\circ} \mathrm{C}$. Prior to the exposure to water, the extent of optical anisotropy of the films is different. The differences in optical properties are due to dissimilarities in the relative humidity of the surrounding ambient atmosphere during sample equilibration (see Table 2). Despite the equal degree of sulfonation, the swelling dynamics and the final degree of swelling are extremely distinct for the two films. The film that has the higher initial anisotropy, $\Delta n=0.028$, swells slower and its swelling factor shows a maximum value of $\sim 3.5$ followed by a continuous relaxation-induced decrease in film thickness. Such overshoot swelling dynamics have been observed for SPEEK and other charged polymers [21-23]. For the film with the lower initial optical anisotropy, $\Delta n=0.023$, the swelling dynamics are much faster. Most of the swelling occurs immediately, upon contact with

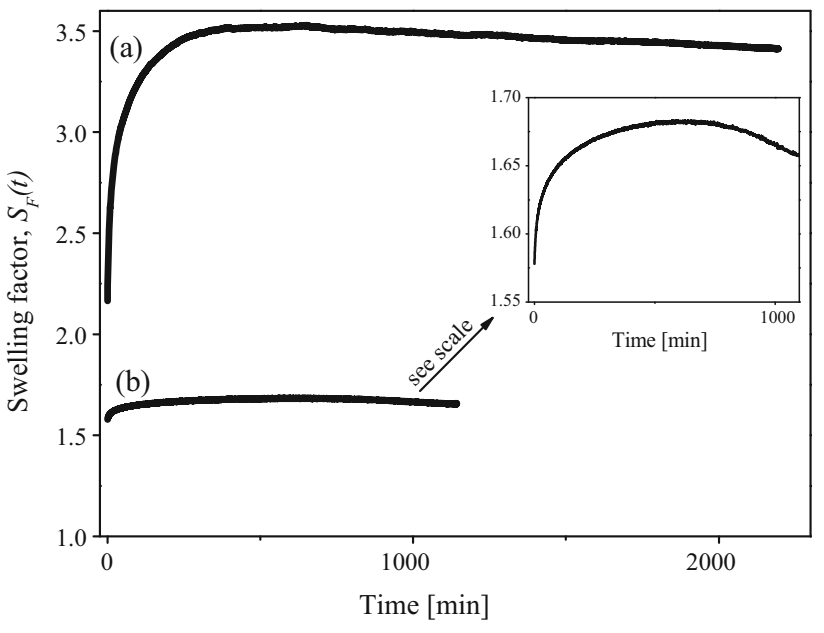

Fig. 2 Time-dependent water-induced swelling at $40{ }^{\circ} \mathrm{C}$ of $\sim 300 \mathrm{~nm}$ SPEEK films with a DS of $84 \%$ and $a$ relatively high optical anisotropy $(\Delta n=0.028)$ and $b$ relatively low optical anisotropy $(\Delta n=0.023)$

water. Closer inspection of the shape of the curve reveals that this film also exhibits overshoot dynamics, albeit far less pronounced, with the maximum swelling factor of only $\sim 1.7$.

In the last years, we have measured the swelling of several dozens of thin SPEEK films and found a positive correlation between the value of $\Delta n$ and the extent of swelling. The observed differences in the swelling behavior can be related to two superimposed phenomena.

Firstly, the distinct swelling behavior can be associated with a different initial concentration of water in the film. Due to the sulfonic acid groups, SPEEK has a high affinity for water. A SPEEK film that is exposed to higher $R H$ of the surrounding ambient atmosphere will have a higher concentration of sorbed water. It is known that a higher water concentration in a SPEEK film results in a reduction of density and anisotropy [14]. The higher initial concentration of water in the film is manifested by a lower value of $\Delta n$ and less apparent swelling during exposure to liquid water. Secondly, the distinct swelling behavior can be due to an inherent relation between optical anisotropy in a film and the swelling of this film. The theoretical prediction of penetrant-induced swelling of polymers is generally based on free energy considerations [24]. Within such a context, the contributions to the free energy that ultimately determine the extent of swelling, are related to the changes in enthalpy and entropy upon mixing of polymer and penetrant, and an elastic contribution due to deformation of the network. The optical anisotropy in the thin films is associated with internal stresses, and consequently constitutes a distinct free energy status prior to swelling. After swelling with water at a high activity ( $\sim 1$, or liquid water), the internal stresses, and hence anisotropy, either vanish or are 
Table 2 Properties of the SPEEK films from Fig. 2

\begin{tabular}{lllllll}
\hline Sample & Nomenclature & $\Delta n(-)$ & $n_{x y}(-)$ & $d_{\text {initial }}(\mathrm{nm})$ & Max. $S_{F}(-)$ & Corresponding $d(t)(\mathrm{nm})$ \\
\hline (a) & 84-2000_humid-20 & 0.028 & 1.648 & 316 & 3.5 & 1106 \\
(b) & 84-2000_humid-50 & 0.023 & 1.659 & 346 & 1.7 & 588 \\
\hline
\end{tabular}

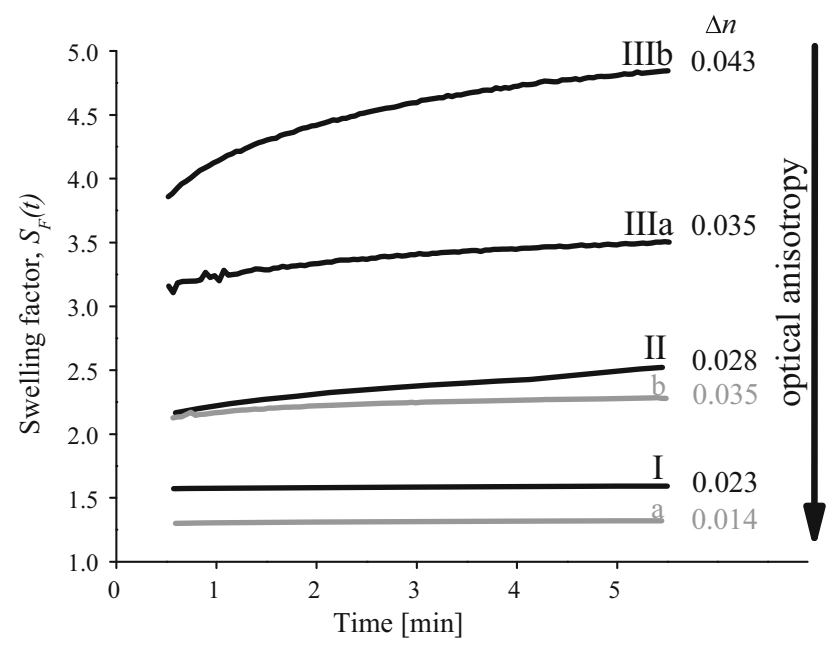

Fig. 3 Water-induced swelling, recorded for 5 min, of SPEEK films with a $D S$ of $84 \%$ and with various initial optical anisotropy, at $20{ }^{\circ} \mathrm{C}$ (gray lines $a$ and $b$ ) and $40{ }^{\circ} \mathrm{C}$ (black lines I, II, IIIa, and IIIb)

very minor. This implies that the distinct initial free energy must result in a distinct extent of swelling.

For both phenomena, a larger extent of optical anisotropy will correspond to a larger extent of swelling, which complicates deconvolution of the two phenomena. This is illustrated by the swelling of a selection of four films at $40{ }^{\circ} \mathrm{C}$ and 2 films at $20^{\circ} \mathrm{C}$, in Fig. 3 (properties of the films are listed in Table 3 ).

All films have been prepared from the batch with a $D S$ of $84 \%$ and have been formed under humid conditions. The four samples swollen at $40{ }^{\circ} \mathrm{C}$ have been obtained from three different sets, I, II, and III, and the swelling of the films has been studied at different times under various relative humidity conditions. Only samples IIIa and IIIb are from the same set and their swelling is studied on the same day, i.e., under the same relative humidity conditions. IIIa and IIIb differ in the extent of optical anisotropy, which has been induced by differences in the spinning conditions [14], 2000 and $3000 \mathrm{rpm}$ for IIIa and IIIb, respectively. The two samples swollen at $20{ }^{\circ} \mathrm{C}$ have been obtained from two different sets, 'a' and 'b.' Sample 'a' with very low optical anisotropy, $\Delta n=0.014$, was exposed prior to swelling to a surrounding ambient atmosphere with $R H \gg 80 \%$ (Table 3).

As we have generally found, the film with the lowest initial optical anisotropy shows the lowest degree of swelling. Because the humidity conditions during the swelling studies of these films are not well defined, it is not possible to quantify the relative contributions of the effect of initial relative humidity and the contribution of the initial stresses and density in the film, to the overall extent of swelling. When comparing samples I, IIIa, and IIIb, the refractive indices of the materials are similar $\left(n_{x y}=1.659\right.$, 1.658 and 1.661 , respectively). This implies a comparable initial density of the samples. Hence, the higher degree of swelling must be predominantly due to initially higher internal stresses in this film. Such an observation is further supported when comparing samples IIIa and IIIb; for these samples, the synthesis and sample equilibration have been identical, except for the spin speed. The consequent difference in optical isotropy of the two films is accompanied by a significant difference in swelling. In this case, this divergent extent of swelling can be attributed to the difference in initial stresses in the two films. Considering Fig. 2, sample 'a' has lower refractive index than sample

Table 3 Properties of the SPEEK films from Fig. 3

\begin{tabular}{|c|c|c|c|c|c|c|}
\hline Sample & Nomenclature & $\Delta n(-)$ & $n_{x y}(-)$ & $d_{\text {initial }}(\mathrm{nm})$ & $S_{F}$ after 5 min. (-) & Corresponding $d(t)(\mathrm{nm})$ \\
\hline \multicolumn{7}{|c|}{ Swelling at $40{ }^{\circ} \mathrm{C}$} \\
\hline $\mathrm{I}$ & 84-2000_humid-50 & 0.023 & 1.659 & 346 & 1.6 & 554 \\
\hline II & 84-2000_humid-20 & 0.028 & 1.648 & 316 & 2.5 & 790 \\
\hline $\mathrm{IIIa}^{\mathrm{a}}$ & 84-2000_humid & 0.035 & 1.658 & 336 & 3.5 & 1176 \\
\hline IIIb & 84-3000_humid & 0.043 & 1.661 & 287 & 4.8 & 1378 \\
\hline \multicolumn{7}{|c|}{ Swelling at $20^{\circ} \mathrm{C}$} \\
\hline a & 84-2000_humid-90 & 0.014 & 1.644 & 340 & 1.3 & 442 \\
\hline $\mathrm{b}$ & 84-2000_humid & 0.035 & 1.658 & 339 & 2.2 & 746 \\
\hline
\end{tabular}

a Samples IIIa, IIIb, and b have been studied under very low $R H$ conditions 
'b' ( $n_{x y}=1.648$ and 1.659, respectively-Table 2$)$, but the extent of swelling is greater for sample ' $a$ '.

Thus, the swelling factor in water of thin SPEEK films is dependent not only on the degree of sulfonation and water temperature, but also on the initial film properties that are strongly responsive to relative humidity degree of the ambient atmosphere to which they are exposed to.

\section{The effect of $\mathrm{RH}=\mathbf{0} \%$ during, and after, film formation on film swelling}

In the above section, a correlation is discussed between the optical anisotropy and swelling of thin SPEEK films, prepared via spin-coating in a humid atmosphere. In a previous paper, we have found that a spin-coating with a relatively concentrated (5 wt\%) SPEEK alcohol solution at relatively low spin speed $(2000 \mathrm{rpm})$, can result in SPEEK films with lower anisotropy as compared to films spun at $3000 \mathrm{rpm}$ [14]. For less concentrated solutions and higher spin speeds, the extent of optical anisotropy of thin SPEEK films is more or less insensitive to variations in the spinning conditions [14]. The anisotropy of the formed films has been also found to increase with a decrease in relative humidity of the surrounding ambient atmosphere [14]. In this paper, a particular swelling behavior is observed when films are prepared by spin-coating in the absence of water ( $R H=0 \%$ due to flushing with nitrogen). The thickness and optical anisotropy of these films are comparable with those of films formed in the presence of water. However, the swelling of the films upon exposure to liquid water is very different. This is illustrated in Fig. 4, by the dynamic swelling of two films with a $D S$ of $84 \%$, of which the optical anisotropy is comparable, $\Delta n \sim 0.028$ (Table 4). Film ' $\mathrm{a}$ ' is prepared under relatively humid conditions $(R H \sim 30 \%)$ and film 'b' under dry nitrogen $(R H=0 \%)$. The film formed under dry conditions shows

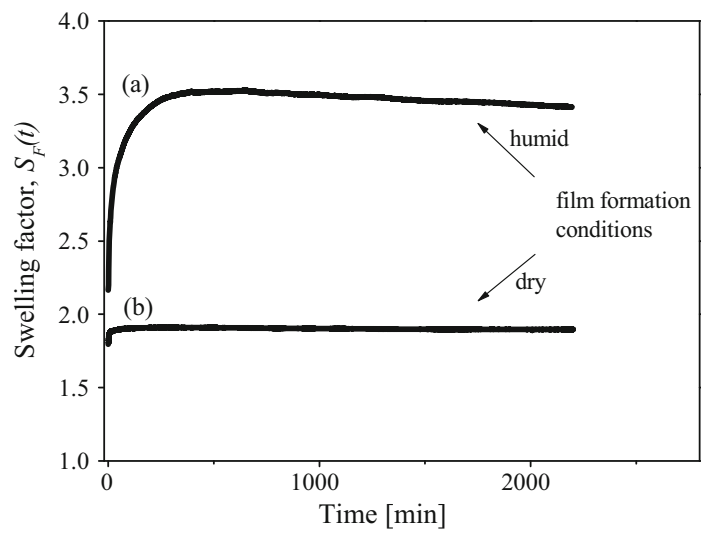

Fig. 4 Water-induced swelling dynamics at $40{ }^{\circ} \mathrm{C}$ of $\sim 300 \mathrm{~nm}$ SPEEK films with a $D S$ of $84 \%$, formed under $a$ humid, $R H \sim 30 \%$ and $b$ dry, $R H=0 \%$ atmosphere. For both films, the extent of optical anisotropy is comparable, $\Delta n=0.028$ significantly less swelling. The different swelling indicates that the hydration state of the polymer, during film formation, affects the final polymer morphology.

It is known that hydration of the negatively charged sulfonic acid groups causes the structural separation of the polymer into hydrophilic domains that are formed from ionic clusters, and hydrophobic domains that are formed from the polymer backbone [25, 26]. The hydrophilic domains are responsible for the transport of water and ions, such as protons, and the hydrophobic domains give the polymer morphological stability [13, 27]. Additionally, Jarumaneeroj et al. recently reported that the absence of water alters reversibly the molecular arrangements in SPEEK [28]. They reported a color change of the material: initially SPEEK is transparent to light in the visible range, upon heating to $190^{\circ} \mathrm{C}$ a yellow color develops. The reduced hydration of the sulfonic acid groups allows them to come closer to each other. This facilitates more pronounced attractive non-covalent interactions between the aromatic rings that are present in the polymer backbone. These attractive interactions are considered to result in an ordered arrangement of the aromatic rings that is referred to as $\pi-\pi$ stacking, which has been further supported with UV-Vis spectroscopy [28]. The reported color change is reversible; upon cooling in ambient or exposure to water, the material becomes transparent again [28].

In Fig. 5, the reversible color change, induced by the removal of water, is shown for a thin $(\sim 800 \mathrm{~nm})$ SPEEK film on top of a porous ceramic $\gamma / \alpha$-alumina support. The usage of ceramic support allows observing the actual colors of coated SPEEK films upon water sorption/desorption. Thin SPEEK films coated on a silicon wafer possess thickness-dependent varieties of colors, caused by light interference between thin layers and the silicon substrate. Those colors also appear to change as the angle of view changes. The color changes of thin SPEEK films coated on a silicon wafer are indicative for the thickness changes upon water sorption/desorption. The film in Fig. 5 was spin-coated on $\gamma / \alpha$-alumina support under humid conditions and initially it is colorless to the human eye (only the white substrate is visible). Figure 5a shows the film directly after incubation at $60{ }^{\circ} \mathrm{C}$ in a vacuum oven. The yellow color is indicative for the changed hydration state and corresponds to the color change reported by Jarumaneeroj et al. at high temperature [28]. The occurrence of the color change at relatively low temperature, in vacuum, implies that it is actually the removal of the water that causes the change in color, rather than an inherent thermochromic characteristic of SPEEK.

Upon the removal of water, an ordered arrangement of the aromatic rings due to non-polar interactions is induced that is destroyed when water molecules are introduced again [28]. Upon exposure to the surrounding humid 
Table 4 Properties of the SPEEK films from Fig. 4

\begin{tabular}{|c|c|c|c|c|c|c|}
\hline Sample & Nomenclature & $\Delta n(-)$ & $n_{x y}(-)$ & $d_{\text {initial }}(\mathrm{nm})$ & Max. $S_{F}(-)$ & Corresponding $d(t)(\mathrm{nm})$ \\
\hline (a) & 84-2000_humid & 0.028 & 1.648 & 316 & 3.5 & 1106 \\
\hline (b) & 84-2000_dry & 0.028 & 1.655 & 291 & 1.9 & 553 \\
\hline
\end{tabular}

(a)

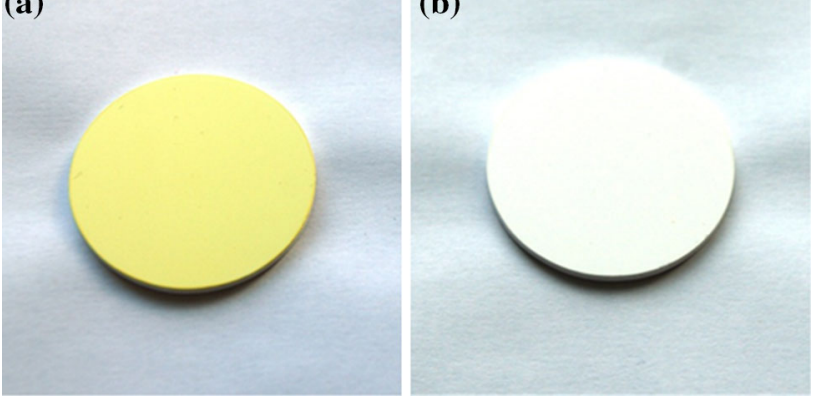

Fig. 5 Photos of a SPEEK film $\sim 800 \mathrm{~nm}$ with a $D S$ of $84 \%$ coated on a $\gamma / \alpha$-alumina support a directly after incubation in a $60{ }^{\circ} \mathrm{C}$ vacuum oven and $\mathbf{b}$ after few minutes in a humid atmosphere

ambient atmosphere, the sorption of water causes the film to become colorless again (Fig. 5b). We have observed that SPEEK membranes with a thickness $>20 \mu \mathrm{m}$ also start to appear yellowish to the human eye, which is caused by slight absorption in the visible range. This yellowish color becomes more apparent with increasing film thickness (the thicker the films, the higher the light absorption) and transforms to intense yellow, which is induced, as reported by Jarumaneeroj et al. [28], by benzene stacking, and is visible in Fig. 5a.

An identical color transformation was observed also for a SPEEK film on top of a porous ceramic $\gamma / \alpha$-alumina support formed under dry nitrogen. Yet the distinct swelling of films prepared under dry conditions (Fig. 4) implies that in that case the morphology of the polymer film is irreversibly affected by the absence of the water during film formation. This is possibly caused by altered microphase separation and the interactions between aromatic rings. Figure 6 shows the dynamic swelling of 12 films, 6 with $D S 68 \%$ and 6 with $D S 84 \%$. The films have been prepared in an identical manner from the same solutions of SPEEK with particular $D S$, except for a difference in relative humidity during spinning (for each $D S, 3$ films have been formed in dry $\mathrm{N}_{2}$, and 3 films in the surrounding humid ambient atmosphere). To some extent, the sample properties slightly deviate. The $\Delta n$ of 84-2000_dry is lower than of 84-2000_humid, but $\Delta n$ of 68-2000_dry is higher than of 68-2000_humid (Table 5). Yet the swelling of films formed without the presence of water is reduced in all cases, and the extent of overshoot swelling and polymer reorganization is minor. The SPEEK films with a lower $D S$ swell also less than those with a higher $D S$, which is

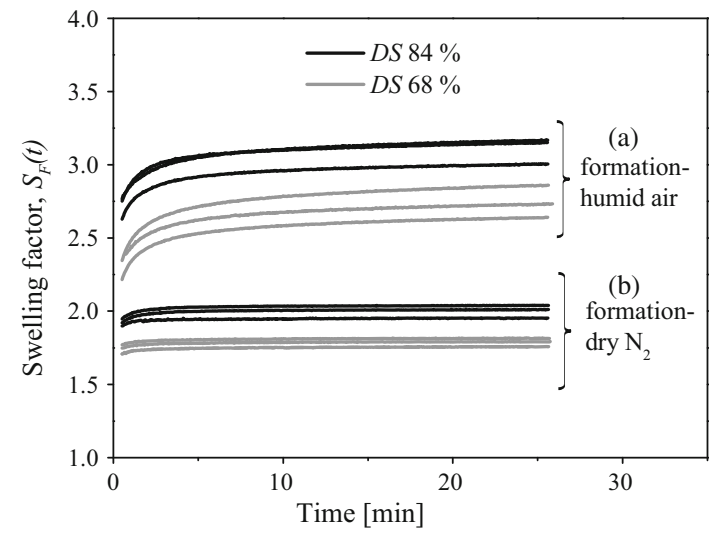

Fig. 6 Time-dependent water-induced swelling (each experiment conducted in triplo) at $40{ }^{\circ} \mathrm{C}$ of $\sim 300 \mathrm{~nm}$ SPEEK films, with a $D S$ of $84 \%$ (black lines) and $68 \%$ (gray lines), formed $a$ in a humid $R H \sim 30 \%$ and $b$ dry $R H=0 \%$ atmosphere. Films are formed simultaneously, in an identical manner from the two methanol solutions of SPEEK DS 68 and $84 \%$, except for a difference in humidity during spinning. All films are measured at the same time, under very low $R H$ conditions

consistent with literature [29]. The swelling experiments confirm the lower propensity to water-induced swelling of films formed under dry conditions. Distinct swelling can have impact on membrane selectivity and stability. In the paper of Zhang et al., SPEEK membranes formed from solvent casting under high relative humidity exhibited the highest proton conductivity, whereas the lowest conductivity was obtained in films formed in dry atmosphere [13]. In general, the lack of water during membrane formation prevents the formation of the ionic clusters of sulfonic acid groups and water, while a percolative network of such clusters is responsible for a high proton conductivity and a high degree of swelling [13, 27, 30]. As such, the properties of thin SPEEK films can be altered without chemical modification, just by varying the humidity during their preparation process.

Table 5 Properties of the SPEEK films from Fig. 6

\begin{tabular}{llll}
\hline Sample nomenclature & $\Delta n(-)$ & $n_{x y}(-)$ & $d_{\text {initial }}(\mathrm{nm})$ \\
\hline 84-2000_humid & $0.033 \pm 0.001$ & $1.652 \pm 0.001$ & $332 \pm 2$ \\
84-2000_dry & $0.029 \pm 0.001$ & $1.648 \pm 0.001$ & $344 \pm 3$ \\
68-2000_humid & $0.033 \pm 0.000$ & $1.656 \pm 0.001$ & $346 \pm 6$ \\
68-2000_dry & $0.036 \pm 0.001$ & $1.655 \pm 0.001$ & $349 \pm 7$ \\
\hline
\end{tabular}

The average values are taken based on 3 samples for each experiment 
To support the differences between SPEEK films formed under humid and dry conditions, negatively charged sulfonic acid groups are labeled with the positively charged fluorescent dye (Rhodamine 6G), and the TIRF microscopy is used to monitor the SPEEK films through the emission of the dye at $520 \mathrm{~nm}$.

The relative humidity during film formation affects the distribution of sulfonic acid groups in SPEEK, as is evident from the TIRF images in Fig. 7. The fluorescent images represent the SPEEK films obtained by using the first experimental method described in the experimental section (film preparation). For the second film formation method, comparable images have been obtained. This confirms that the presence of the dye molecules does not interfere or alter the structural arrangements of SPEEK in a substantial manner. Figure $7 \mathrm{a}$ is representative for samples prepared under humid conditions. Such films show a homogenous distribution of the fluorescent cations, and thus of the sulfonic acid groups. When the film is formed in dry conditions, a manifestly different distribution of sulfonic acid groups is observed (Fig. 7b), indicating an altered morphology of the film. This altered film morphology is irreversible upon the exposure of the film to moisture, in contrary to reversible $\pi-\pi$ stacking, and results in lower propensity to water-induced swelling.

For relatively thick films, the effect of water on microphase-separated morphology can be studied using SAXS, as has been reported by Swier et al. for sulfonated poly (ether ketone ketone) (SPEKK) [31]. They confirmed that the water-swollen membrane exhibit a microphase-separated morphology, consisting of water-swollen ionic domains and a non-polar phase. For the dry sample, no phase separation was observed, but this is possibly due to insufficient electron density contrast between the acidic domains and the PEKK matrix [31]. It has to be noted that our investigation compares the swelling behavior and TIRF
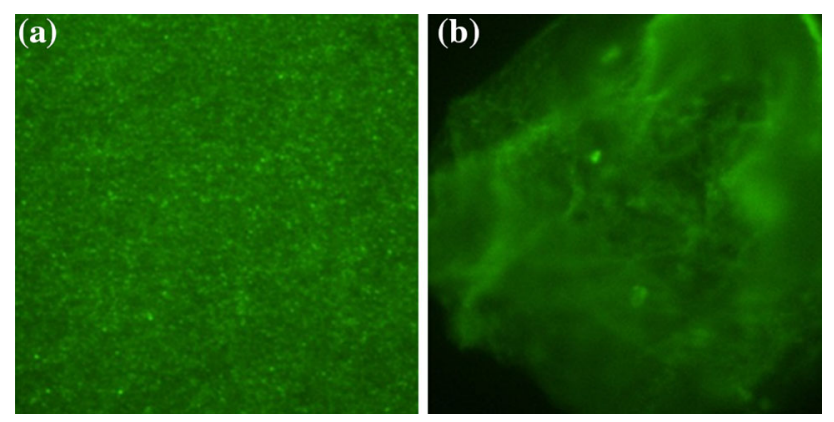

Fig. 7 Fluorescence microscopy images of SPEEK films (DS of $84 \%$ ) labeled with Rhodamine $6 \mathrm{G}$, formed under a humid ambient and $\mathbf{b}$ dry conditions. The Rhodamine $6 \mathrm{G}$ was excited using $488 \mathrm{~nm}$ laser and the emission signal from the green dye was collected at $520 \mathrm{~nm}$. Image size corresponds to a region of $28 \times 28 \mu \mathrm{m}^{2}$ for both images images (Figs. 6, 7, respectively) of the two different thin films that are both in a hydrated state (films are measured in identical $R H$ conditions); the thin film formation is executed either under humid or dry conditions. This is in contrast to the research of Swier et al., who studied films in a dry state. Hence, their results cannot be directly compared with our results. The possible interactions and ordered arrangement of the aromatic rings ( $\pi-\pi$ stacking) in the films formed without the presence of water, could be investigated on thicker films, for instance, using XRD [32, 33]. Our films are too thin for a conclusive X-Ray scattering study, we have encountered the problems presented in the review [34], and could not detect the structural differences between the SPEEK films formed under dry and humid conditions. Yet the distinct distribution of hydrophilic and hydrophobic domains in those SPEEK films is conclusively shown with TIRF and the altered propensity to water-induced swelling is proven using SE. This is in line with the research of Zhang et al. who also inferred based on the SEM and XPS analysis that water in the environment during formation not only leads to the phase separation in SPEEK, but also induces the orientation arrangement of sulfonic acid groups [13].

\section{Conclusions}

Water-induced swelling in thin oriented sulfonated poly (ether ether ketone) films has been studied using in situ spectroscopic ellipsometry. For films with a comparable degree of sulfonation, the swelling behavior is significantly correlated with the extent of optical anisotropy. Films with high optical anisotropy swell considerably more than less anisotropic films. The correlation is attributed to two superimposed phenomena; a higher anisotropy can imply a lower initial water concentration at the start of the experiments, and a higher anisotropy is associated with higher internal stresses that imply a distinct free energy status. At very low water concentration, assembly of the aromatic rings in the backbone of the polymer can occur, which is manifested by a color change from clear to intense yellow. When the polymer is deprived of water during film formation, the film morphology is affected. This results in a lower propensity of the films to swell in water, signifying that control of the humidity during film formation allows changing the final film properties, without chemical modification.

Acknowledgements This work was performed in the cooperation framework of Wetsus, centre of excellence for sustainable water technology (www.wetsus.nl). Wetsus is co-funded by the Dutch Ministry of Economic Affairs and Ministry of Infrastructure and Environment, the European Union Regional Development Fund, the Province of Fryslân, and the Northern Netherlands Provinces. The 
authors would like to thank the participants of the research theme "Dehydration" for the fruitful discussions and their financial support.

Open Access This article is distributed under the terms of the Creative Commons Attribution 4.0 International License (http://crea tivecommons.org/licenses/by/4.0/), which permits unrestricted use, distribution, and reproduction in any medium, provided you give appropriate credit to the original author(s) and the source, provide a link to the Creative Commons license, and indicate if changes were made.

\section{References}

1. Kreuer KD (1997) On the development of proton conducting materials for technological applications. Solid State Ion 97(1-4):1-15

2. Gómez P, Daviou MC, Ibáñez R, Eliceche AM, Ortiz I (2006) Comparative behaviour of hydrophilic membranes in the pervaporative dehydration of cyclohexane. J Membr Sci 279(1-2): 635-644

3. Huang RYM, Shao P, Feng X, Burns CM (2001) Pervaporation separation of water/isopropanol mixture using sulfonated poly(ether ether ketone) (SPEEK) membranes: transport mechanism and separation performance. J Membr Sci 192(1-2):115-127

4. Sijbesma H, Nymeijer K, van Marwijk R, Heijboer R, Potreck J, Wessling M (2008) Flue gas dehydration using polymer membranes. J Membr Sci 313(1-2):263-276

5. Toomey R, Freidank D, Rühe J (2004) Swelling behavior of thin, surface-attached polymer networks. Macromolecules 37(3): 882-887

6. Hou H, Di Vona ML, Knauth P (2012) Building bridges: crosslinking of sulfonated aromatic polymers-a review. J Membr Sci 423-424:113-127

7. Di Vona ML, Ahmed Z, Bellitto S, Lenci A, Traversa E, Licoccia S (2007) SPEEK-TiO2 nanocomposite hybrid proton conductive membranes via in situ mixed sol-gel process. J Membr Sci 296(1-2):156-161

8. Unnikrishnan L, Mohanty S, Nayak SK (2013) Proton exchange membranes from sulfonated poly(ether ether ketone) reinforced with silica nanoparticles. High Perform Polym 25(7):854-867

9. Shao P, Huang RYM, Feng X, Anderson W, Pal R, Burns CM (2005) Composite membranes with an integrated skin layer: preparation, structural characteristics and pervaporation performance. J Membr Sci 254(1-2):1-11

10. Dishari SK, Hickner MA (2012) Antiplasticization and water uptake of nafion thin films. ACS Macro Lett 1(2):291-295

11. Eastman SA, Kim S, Page KA, Rowe BW, Kang S, Soles CL, Yager KG (2012) Effect of confinement on structure, water solubility, and water transport in Nafion thin films. Macromolecules 45(19):7920-7930

12. Krishnan K, Iwatsuki H, Hara M, Nagano S, Nagao Y (2014) Proton conductivity enhancement in oriented, sulfonated polyimide thin films. J Mater Chem A 2(19):6895-6903

13. Zhang Y, Ge J, Cui Z, Liu C, Xing W, Zhang J, Lin H, Na H (2010) Proton conductivity enhancement by nanostructural control of sulphonated poly (ether ether ketone) membranes. Int $\mathbf{J}$ Hydrog Energy 35(15):8337-8342

14. Koziara BT, Nijmeijer K, Benes NE (2015) Optical anisotropy, molecular orientations, and internal stresses in thin sulfonated poly(ether ether ketone) films. J Mater Sci 50(8):3031-3040. doi:10.1007/s10853-015-8844-0
15. Shibuya N, Porter RS (1992) Kinetics of PEEK sulfonation in concentrated sulfuric acid. Macromolecules 25(24):6495-6499

16. Reyna-Valencia A, Kaliaguine S, Bousmina M (2005) Tensile mechanical properties of sulfonated poly(Ether Ether Ketone) (SPEEK) and BPO4/SPEEK membranes. J Appl Polym Sci 98(6):2380-2393

17. Luiten MWJ, Benes NE, Huiskes C, Kruidhof H, Nijmeijer A (2010) Robust method for micro-porous silica membrane fabrication. J Membr Sci 348(1-2):1-5

18. Ogieglo W, Wormeester H, Wessling M, Benes NE (2013) Temperature-induced transition of the diffusion mechanism of n-hexane in ultra-thin polystyrene films, resolved by in situ spectroscopic ellipsometry. Polymer 54(1):341-348

19. Tompkins HG, Irene EA (2005) Handbook of Ellipsometry. William Andrew Publishing, Norwich, NY

20. Fujiwara H (ed) (2007) Principles of spectroscopic ellipsometry. In: Spectroscopic ellipsometry. Wiley: New York, pp 81-146. doi:10.1002/9780470060193.ch4

21. Ogieglo W, De Grooth J, Wormeester H, Wessling M, Nijmeijer K, Benes NE (2013) Relaxation induced optical anisotropy during dynamic overshoot swelling of zwitterionic polymer films. Thin Solid Films 545:320-326

22. Potreck J, Uyar F, Sijbesma H, Nijmeijer K, Stamatialis D, Wessling M (2009) Sorption induced relaxations during water diffusion in S-PEEK. Phys Chem Chem Phys 11(2):298-308

23. Walker M, Baumgärtner KM, Kaiser M, Kerres J, Ullrich A, Räuchle E (1999) Proton-conducting polymers with reduced methanol permeation. J Appl Polym Sci 74(1):67-73

24. Flory PJ (1953) Principles of polymer chemistry. Cornell University, Ithaca

25. Gil M, Ji X, Li X, Na H, Hampsey JE, Lu Y (2004) Direct synthesis of sulfonated aromatic poly(ether ether ketone) proton exchange membranes for fuel cell applications. J Membr Sci 234(1-2):75-81

26. Kreuer KD, Portale G (2013) A critical revision of the nanomorphology of proton conducting ionomers and polyelectrolytes for fuel cell applications. Adv Funct Mater 23(43):5390-5397

27. Kreuer KD (2001) On the development of proton conducting polymer membranes for hydrogen and methanol fuel cells. J Membr Sci 185(1):29-39

28. Jarumaneeroj C, Tashiro K, Chirachanchai S (2014) Shifting from hydrogen bond network to $\pi-\pi$ Stacking: a key mechanism for reversible thermochromic sulfonated poly(ether ether ketone). Macromol Rapid Commun 35(16):1397-1401

29. Li L, Zhang J, Wang Y (2003) Sulfonated poly(ether ether ketone) membranes for direct methanol fuel cell. J Membr Sci 226(1-2):159-167

30. Gupta M, Deshpande AP, Kumar PBS (2014) Rheology of concentrated sulfonated poly(ether ether ketone) solutions. J Appl Polym Sci 131(7):40044

31. Swier S, Chun YS, Gasa J, Shaw MT, Weiss RA (2005) Sulfonated poly(ether ketone ketone) ionomers as proton exchange membranes. Polym Eng Sci 45(8):1081-1091

32. Sinnokrot MO, Valeev EF, Sherrill CD (2002) Estimates of the Ab Initio Limit for $\pi-\pi$ Interactions: the Benzene Dimer. J Am Chem Soc 124(36):10887-10893

33. Dahl T (1994) The nature of stacking interactions between organic molecules elucidated by analysis of crystal structures. Acta Chem Scand 48:96-106

34. Paul FF (1996) X-ray analysis of thin films and multilayers. Rep Prog Phys 59(11):1339 